\title{
Mechanical Property and Analysis of Asphalt Components Based on Molecular Dynamics Simulation
}

\author{
Rui Li, ${ }^{1,2}$ Qiqi Guo, ${ }^{1}$ Hui Du, ${ }^{3}$ and Jianzhong Pei ${ }^{1}$ \\ ${ }^{1}$ School of Highway, Chang'an University, Xi'an 710064, China \\ ${ }^{2}$ School of Materials Science and Engineering, Nanyang Technological University, Singapore 639798 \\ ${ }^{3}$ School of Transportation Engineering, Southeast University, Nanjing 210096, China \\ Correspondence should be addressed to Jianzhong Pei; peijianzhong@126.com
}

Received 31 July 2017; Accepted 28 September 2017; Published 26 October 2017

Academic Editor: Tomokazu Yoshimura

Copyright (C) 2017 Rui Li et al. This is an open access article distributed under the Creative Commons Attribution License, which permits unrestricted use, distribution, and reproduction in any medium, provided the original work is properly cited.

\begin{abstract}
The asphalt-aggregate interface interaction plays a significant role in the overall performances of asphalt mixture. In order to analyze the chemical constitution of asphalt effects on the asphalt-aggregate interaction, the average structure $\mathrm{C}_{64} \mathrm{H}_{52} \mathrm{~S}_{2}$ is selected to represent the asphalt, and the colloid, saturated phenol, and asphaltene are selected to represent the major constitutions in asphalt. The molecular models are established for the three compositions, respectively, and the Molecular Dynamics (MD) simulation was conducted for the three kinds of asphaltene-aggregate system at different presses. Comparing the $E$ value of Young modulus of these three polymers, the maximum modulus value of asphaltene was $2.80 \mathrm{GPa}$, the modulus value of colloid was secondary, and the minimum modulus of saturated phenol was $0.52 \mathrm{GPa}$. This result corresponds to conventional understanding.
\end{abstract}

\section{Introduction}

At present, scholars at home and abroad have more and more research perspectives on polymer materials [1-3]. Besides, the research process and methods are also diverse. Since the materials prepared indoors and tested will be influenced by the factors of temperature and pressure, there are also some potential uncontrollable variables which will result in the fact that the depth of analytical investigation on experimental data will be limited $[4,5]$. However, researchers have extended the material research field continuously thanks to the introduction of Molecular Dynamics method in recent years. With this simulation method, various parameters can be controlled, and even the environment that can not be realized in laboratory can be simulated [6]. Thus, it will be an important tendency of studying polymer materials to apply Molecular Dynamics method to predict and study the polymer materials' properties gradually [7-9].

In order to analyze the chemical constitution of asphalt on the AAI, the average structure $\mathrm{C}_{65} \mathrm{H}_{74} \mathrm{~N}_{2} \mathrm{~S}_{2}$ is selected in this paper to represent the asphalt and the colloid; saturated phenol and asphaltene are selected to represent the major constitution in asphalt. The molecular models are established for the three compositions, respectively, and the MD simulation was conducted for the three kinds of asphalteneaggregate system at different presses.

\section{Modeling}

When the force acts on the system and if the whole system is balanced, the external force suffered in the system will have an absolute balance with the internal force generated inside the system. Normally, stress can be expressed as a second-order tensor containing 9 components as shown in

$$
\left(\begin{array}{lll}
\sigma_{11} & \sigma_{12} & \sigma_{13} \\
\sigma_{21} & \sigma_{22} & \sigma_{23} \\
\sigma_{31} & \sigma_{32} & \sigma_{33}
\end{array}\right)
$$

In the process of molecular calculation, internal stress tensor can be expressed by the virial expression of

$$
\sigma=-\frac{1}{V_{0}}\left[\left(\sum_{i=1}^{N} m_{i}\left(V_{i} V_{i}^{T}\right)\right)+\left(\sum_{i<j} r_{i j} f_{i j}^{T}\right)\right] .
$$


In formula (2), $i$ represents the sequence numbers (from 1 to $N$ ) of particles; $m_{i}, V_{i}$, and $f_{i}$ represent the mass, speed, and force suffered of number $i$. $V_{0}$ refers to the volume of system without deformation.

Once stress acts on the molecular system, the position of internal particles of system will change relatively, where the change is expressed by the strain tensor of

$$
\left(\begin{array}{lll}
\varepsilon_{11} & \varepsilon_{12} & \varepsilon_{13} \\
\varepsilon_{21} & \varepsilon_{22} & \varepsilon_{23} \\
\varepsilon_{31} & \varepsilon_{32} & \varepsilon_{33}
\end{array}\right)
$$

For the parallel hexahedron structured in this paper, strain tensor is only determined by the column vectors $a_{0}$, $b_{0}$, and $c_{0}$ and deformation state vectors $a, b$, and $c$ under a certain condition, as shown in

$$
\varepsilon=\frac{1}{2}\left[\left(h_{0}^{T}\right)^{-1} G h_{0}^{-1}-1\right]
$$

where $h_{0}$ represents the matrix structured by vectors $a_{0}, b_{0}$, and $c_{0}$. $h$ refers to the matrix structured by deformation state vectors $a, b$, and $c$. $G$ represents $h^{T} h$.

Elastic stiffness constant is associated with the different compositions of system stress and strain. With regard to small deformation, the relationship between stress and strain meets Hooke's law, as shown in

$$
\sigma_{i m}=\mathrm{C}_{i m n k} \varepsilon_{n k},
$$

where $\mathrm{C}_{\text {imnk }}$ refers to the elastic stiffness constant.

Since stress tensor and strain tensor have some symmetry, stress formula (1) can be simplified as

$$
\left(\begin{array}{lll}
\sigma_{11} & \sigma_{12} & \sigma_{13} \\
\sigma_{21} & \sigma_{22} & \sigma_{23} \\
\sigma_{31} & \sigma_{32} & \sigma_{33}
\end{array}\right) \longrightarrow\left(\begin{array}{lll}
\sigma_{1} & \sigma_{6} & \sigma_{5} \\
\sigma_{6} & \sigma_{2} & \sigma_{4} \\
\sigma_{5} & \sigma_{4} & \sigma_{3}
\end{array}\right)
$$

Stain formula (3) can be simplified as

$$
\left(\begin{array}{lll}
\varepsilon_{11} & \varepsilon_{12} & \varepsilon_{13} \\
\varepsilon_{21} & \varepsilon_{22} & \varepsilon_{23} \\
\varepsilon_{31} & \varepsilon_{32} & \varepsilon_{33}
\end{array}\right) \rightarrow\left(\begin{array}{ccc}
\varepsilon_{1} & \frac{\varepsilon_{6}}{2} & \frac{\varepsilon_{5}}{2} \\
\frac{\varepsilon_{6}}{2} & \varepsilon_{2} & \frac{\varepsilon_{4}}{2} \\
\frac{\varepsilon_{5}}{2} & \frac{\varepsilon_{4}}{2} & \varepsilon_{3}
\end{array}\right)
$$

Suppose that the materials prepared are isotropic, and the stress and strain only depend on two independent coefficients. Stiffness matrix is shown as

$$
\left(\begin{array}{cccccc}
\lambda+2 \mu & \lambda & \lambda & 0 & 0 & 0 \\
\lambda & \lambda+2 \mu & \lambda & 0 & 0 & 0 \\
\lambda & \lambda & \lambda+2 \mu & 0 & 0 & 0 \\
0 & 0 & 0 & \mu & 0 & 0 \\
0 & 0 & 0 & 0 & \mu & 0 \\
0 & 0 & 0 & 0 & 0 & \mu
\end{array}\right),
$$

where $\lambda$ and $\mu$ in formula (8) are called lame constants.
In addition, with regard to isotropic materials, the Yong modulus $E$, Poisson's ratio $v$, bulk modulus $K$, and shear modulus $G$ can be obtained through lame constants $\lambda$ and $\mu$, as shown in

$$
\begin{aligned}
& E=\frac{\mu(3 \lambda+2 \mu)}{\lambda+\mu}, \\
& \nu=\frac{\lambda}{2(\lambda+\mu)}, \\
& K=\lambda+\frac{2}{3 \mu}, \\
& G=\mu,
\end{aligned}
$$

where Poisson's ratio can combine with these four parameters, and the relationship is shown in

$$
E=2 G(1+\nu)=3 K(1-2 \nu) .
$$

\section{Results and Discussion}

\subsection{Mechanical Property Simulation Analysis of Colloid}

(1) Simulation Process and Result of Molecular Dynamics. The 1,7-dimethylnaphthalene was used as the repetitive unit to represent colloid in this paper. According to the suggestions of literature, macromolecular structure obtained at the polymerization degree in the range of $10 \sim 15$ was employed $[10,11]$. The character after calculation could meet the requirements such as research precision. The degree of polymerization selected for structuring the macromolecular chain of colloid was 15 , and the degree of polymerization that was 15 to structure the long chain of colloid is shown in Figure 1.

Forcite module was used to analyze geometry optimization for the long chain of colloid. Figure 2 is the long chain of colloid after geometry optimization.

Afterwards, a cubic vacuum space in $60 \AA \times 60 \AA \times 60 \AA$ was structured. The density was set at $0.1 \mathrm{~g} / \mathrm{cm}^{3}$, and the initial model of colloid unit cell at the density of 0.1 obtained is shown in Figure 3.

The density of initial model is $0.1 \mathrm{~g} / \mathrm{cc}$, and the density was in the range of $0.99 \sim 1.1 \mathrm{~g} / \mathrm{cm}^{3}$ at abnormal temperature; however, the low density system of Figure 3 is usually in a high energy state. Thus, structural optimization should be conducted to the system first to lower the potential energy, and then forcite can be used for optimization. When dynamic calculation was conducted, the temperature was $298 \mathrm{~K}$ (close to normal temperature), simulation time was $200 \mathrm{ps}$ and pressure was $0.01 \mathrm{GPa}$, and the initial density of model at 0.1 would be compressed. In the simulation process, temperature, energy, system density, and the length of side of system were changing continually. The output images are shown from Figures 4-7, where the system energy of Figure 5 changed with simulation time. Figure 4(a) was the whole temperature changing process, and Figure 4(b) was the result after enlarging part of it.

It can be seen from Figure 4(a) that the temperature gradually fluctuated around $298 \mathrm{~K}$. It can be seen from 


\section{tos}

Figure 1: Long chain of colloid for the degree of polymerization at 15.

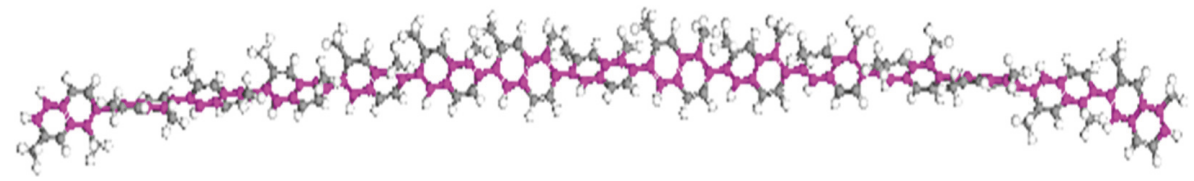

FIGURE 2: Long chain of colloid after being geometrically optimized.

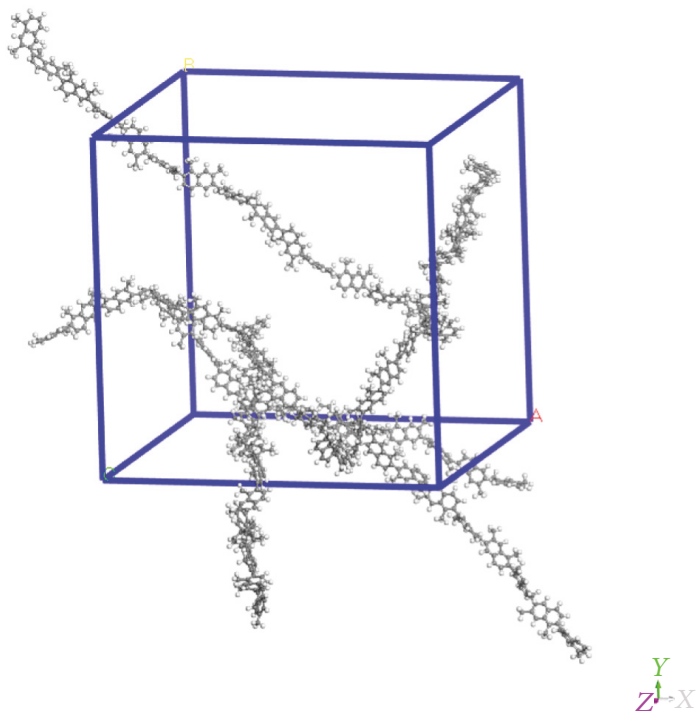

FIGURE 3: Initial model of colloid at the density of 0.1 .

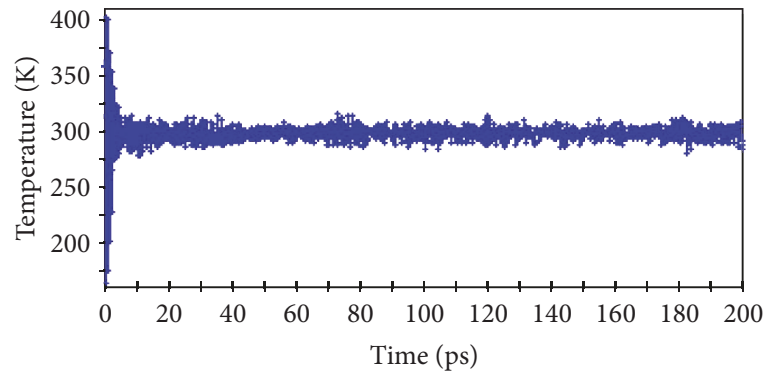

(a) System temperature fluctuated

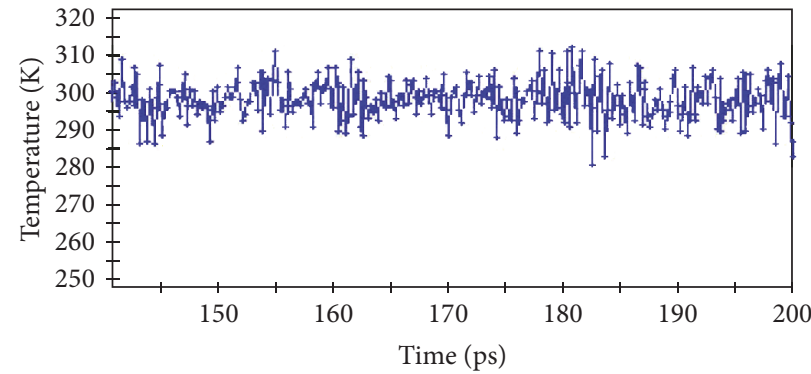

(b) Partial enlarged detail of temperature change

FIGURE 4: Change graph of temperature with simulation time after NPT dynamics finished.

Figure 4 (b) that the fluctuation range was smaller $\left( \pm 10^{\circ} \mathrm{C}\right)$. The energy tended to be convergent gradually, suggesting that the system reached a balance after dynamic simulation.

It was obtained from Figure 6 that the system was continuously pressured, the density of system increased, the length of side decreased, and system was compressed $100 \mathrm{ps}$ before the process of simulation. After 100 ps, the system tended to be balanced, and the parameters tended to be stable.
When the pressure increased to $0.08 \mathrm{GPa}$, the simulation time was $200 \mathrm{ps}$, the system was compressed, the length of side decreased, and the density increased again. The curves of system density and the length of side changing with time are shown in Figure 7.

It can be seen from Figure 7 that the system was further compressed when the pressure of system increased to $0.08 \mathrm{GPa}$. It was found in Figure 7 that the system density 


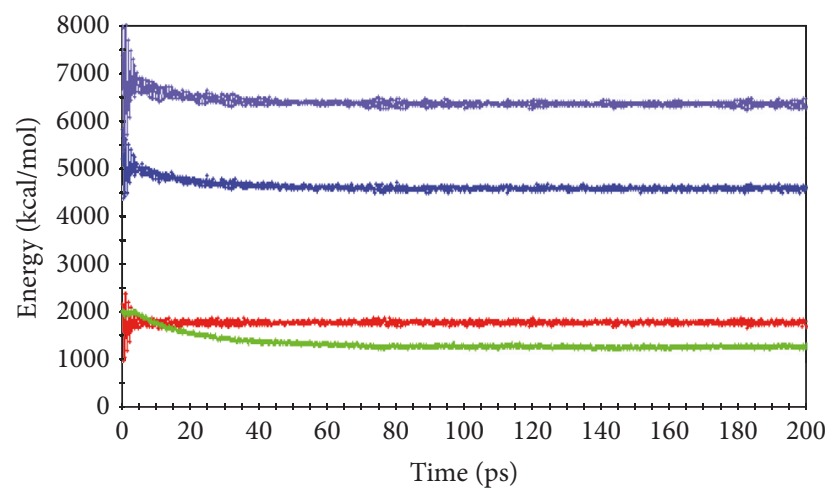

FIGURE 5: Change of system energy with simulation time.

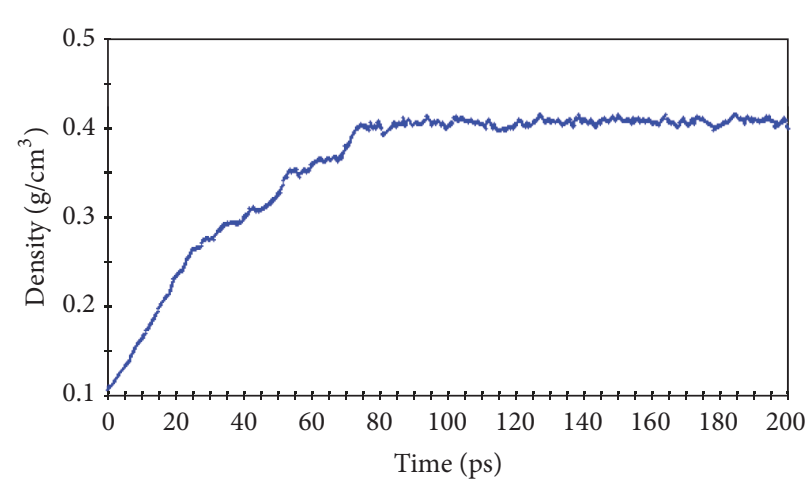

(a)

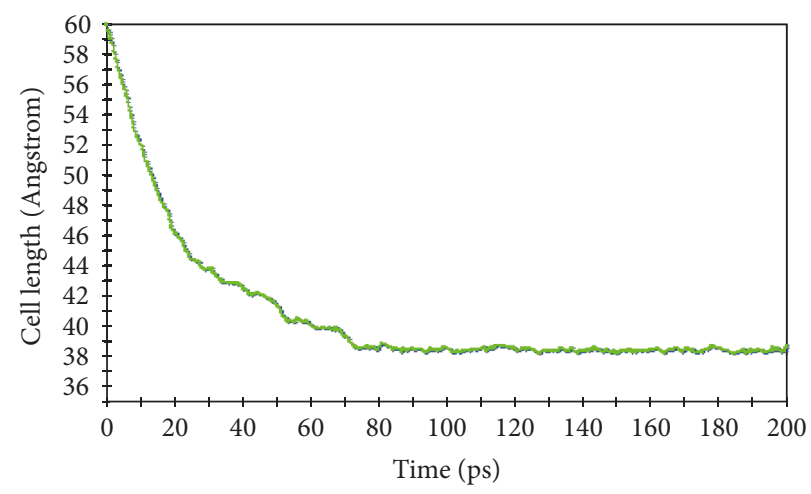

(b)

Figure 6: Change of (a) system density and (b) system length of side with time.

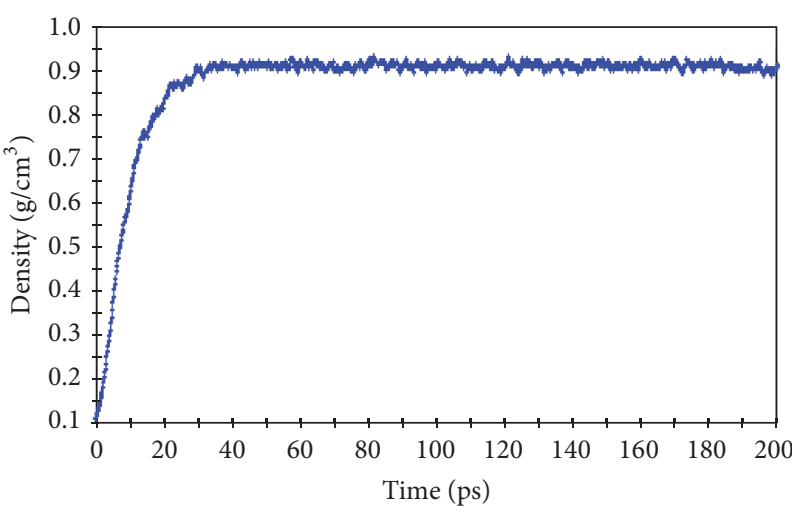

(a)

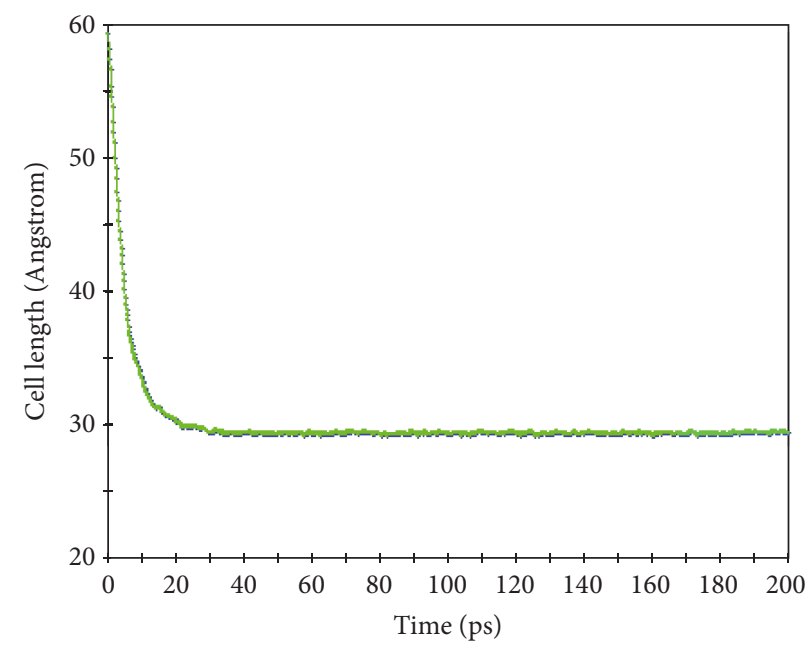

(b)

Figure 7: Change of (a) system density and (b) system length of side with time at $0.08 \mathrm{GPa}$.

was very close to the true density of colloid. At this moment, the system reached a balance again, and then there was a NPT balance lasting for $500 \mathrm{ps}$ at $0.09 \mathrm{GPa}$. The increasing amplitude of density was limited. After verification, when the pressure was up to $0.09 \mathrm{GPa}$ and increasing constantly, the changes of system density and length of side were very small. Finally, the system density and length of side at 0.09 GPa were used as the ultimate model to test the mechanical property of 
TABLE 1: Stiffness matrix obtained from colloid model (GPa).

\begin{tabular}{|c|c|c|c|c|c|c|}
\hline $\mathrm{C}_{i j}$ & 1 & 2 & 3 & 4 & 5 & 6 \\
\hline 1 & 4.5089 & 2.8995 & 3.1170 & 0.1436 & 0.4446 & -0.3247 \\
\hline 2 & 2.8995 & 6.6093 & 3.5637 & -0.0619 & -0.4925 & 0.2330 \\
\hline 3 & 3.1170 & 3.5637 & 4.5407 & 0.9075 & 0.6968 & -0.1275 \\
\hline 4 & 0.1436 & -0.0619 & 0.9075 & 1.5682 & 0.5402 & 0.2406 \\
\hline 5 & 0.4446 & -0.4925 & 0.6968 & 0.5402 & 1.1374 & -0.0765 \\
\hline 6 & -0.3247 & 0.2330 & -0.1275 & 0.2406 & -0.0765 & 0.0809 \\
\hline
\end{tabular}

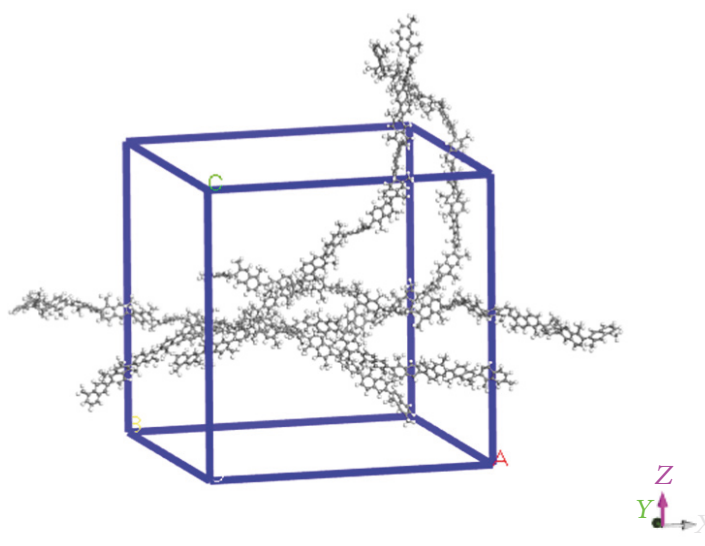

FIGURE 8: Ultimately obtained colloid system.

colloid. The system at the moment is shown in Figure 8. The density at this moment was $0.99 \mathrm{~g} / \mathrm{cm}^{3}$.

(2) Stiffness Matrix and Mechanical Parameters of Colloid. With regard to the subsequently conducted operation and calculation processes to mechanical properties, the program will impose strains in the modes of 100000, 010000, 001000, 000100,000010 , and 000001 on the system model. These strains act on the directions of $X X \cdot Y Y \cdot Z Z \cdot Y Z \cdot Z X$. $X Y$ of the mode. In each mode, four strain values \pm 0.001 and \pm 0.003 will be imposed. The default value of software is the maximum value of 0.003 . Under this strain loading, the corresponding stress will be obtained, and the corresponding stiffness constant $C_{i j}$ will be obtained with this result to further obtain the elastic stiffness matrix of colloid mode, as shown in Table 1.

It can be seen from Table 1 that the values of $\mathrm{C}_{14}, \mathrm{C}_{15}$, $\mathrm{C}_{16}, \mathrm{C}_{24}, \mathrm{C}_{25}, \mathrm{C}_{26}, \mathrm{C}_{34}, \mathrm{C}_{35}, \mathrm{C}_{36}, \mathrm{C}_{45}, \mathrm{C}_{46}$, and $\mathrm{C}_{56}$ are close to 0 , but, for the groups of $\mathrm{C}_{11}, \mathrm{C}_{22}, \mathrm{C}_{33}, \mathrm{C}_{12}, \mathrm{C}_{13}, \mathrm{C}_{23}$ and $\mathrm{C}_{44}, \mathrm{C}_{55}$, and $\mathrm{C}_{66}$, the values in each group are very close, suggesting that the colloid model of Figure 10 is close to isotropy. Suppose the material is isotropic, and the calculation of lame constant is shown in

$$
\begin{aligned}
\lambda & =\frac{1}{3}\left(\mathrm{C}_{11}+\mathrm{C}_{22}+\mathrm{C}_{33}\right)-\frac{2}{3}\left(\mathrm{C}_{44}+\mathrm{C}_{55}+\mathrm{C}_{66}\right) \\
& =3.3620 \mathrm{GPa}, \\
\mu & =\frac{1}{3}\left(\mathrm{C}_{44}+\mathrm{C}_{55}+\mathrm{C}_{66}\right)=0.9288 \mathrm{GPa} .
\end{aligned}
$$

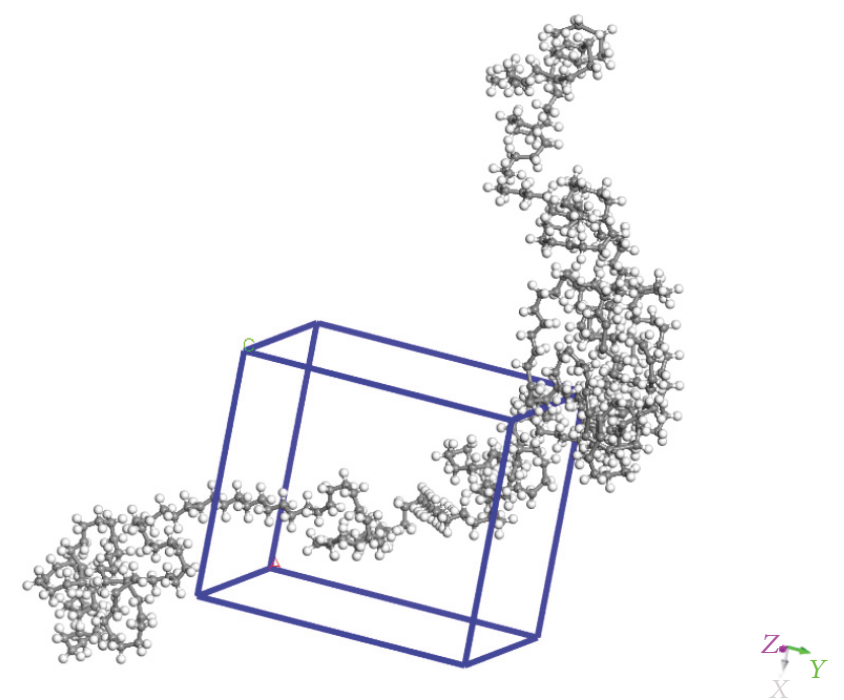

FIGURE 9: Initial model of saturated phenol at the density of 0.1 .

After substituting $\lambda=3.3620 \mathrm{GPa}$ and $\mu=0.9288 \mathrm{GPa}$ into formula (9), the mechanical parameters of colloid were obtained below:

$$
\begin{aligned}
E & =2.59 \mathrm{GPa} ; \\
v & =0.39 ; \\
K & =4.08 \mathrm{GPa} ; \\
G & =0.93 \mathrm{GPa} .
\end{aligned}
$$

\subsection{Mechanical Property Simulation Analysis of Saturated Phenol}

(1) Simulation Process and Result of Molecular Dynamics. The linear chain $\left(n-\mathrm{C}_{22} \mathrm{H}_{46}\right)$ was selected to represent saturated phenol, and the degree of polymerization at 10 was selected to structure saturated phenol model. The model was optimized and placed into the cubic vacuum space where the length of three sides was $6 \mathrm{~nm}$. The initial density was set at $0.1 \mathrm{~g} / \mathrm{cm}^{3}$, and the initial saturated phenol model was obtained as shown in Figure 9.

The true saturated density is $0.7944 \mathrm{~g} / \mathrm{cc}$, and thus the system should be compressed to increase the density and 
TABLE 2: Stiffness matrix obtained for saturated phenol model.

\begin{tabular}{lcccccc}
\hline $\mathrm{C}_{i j}$ & 1 & 2 & 3 & 4 & 5 & \multicolumn{1}{c}{6} \\
\hline 1 & 1.7170 & 1.3630 & 1.8868 & -0.2839 & 0.4201 & 0.4593 \\
2 & 1.3630 & 2.0288 & 2.0845 & -0.3727 & 0.2747 & 0.0954 \\
3 & 1.8868 & 2.0845 & 1.7931 & -0.1096 & 0.2204 & -0.0308 \\
4 & -0.2829 & -0.3727 & -0.1096 & 0.1437 & -0.0936 & 0.1666 \\
5 & 0.4201 & 0.2747 & 0.2204 & -0.0936 & -0.1628 & -0.1628 \\
6 & -0.4593 & 0.0954 & -0.0308 & 0.1666 & 0.2710 \\
\hline
\end{tabular}

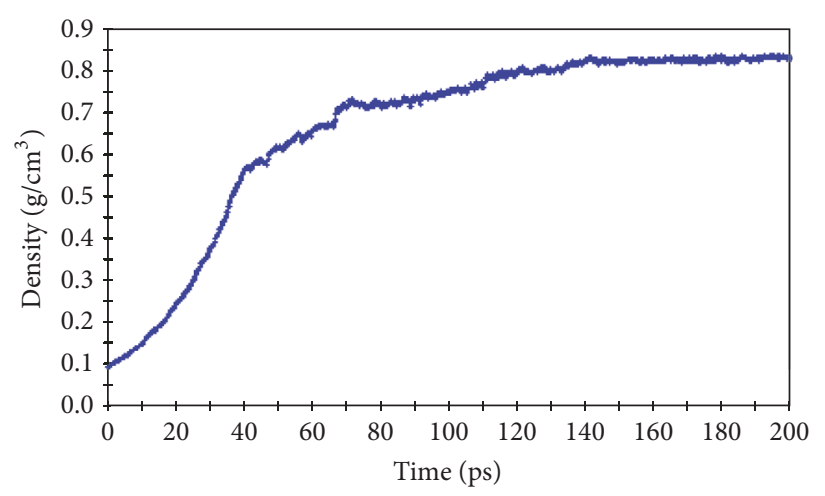

(a)

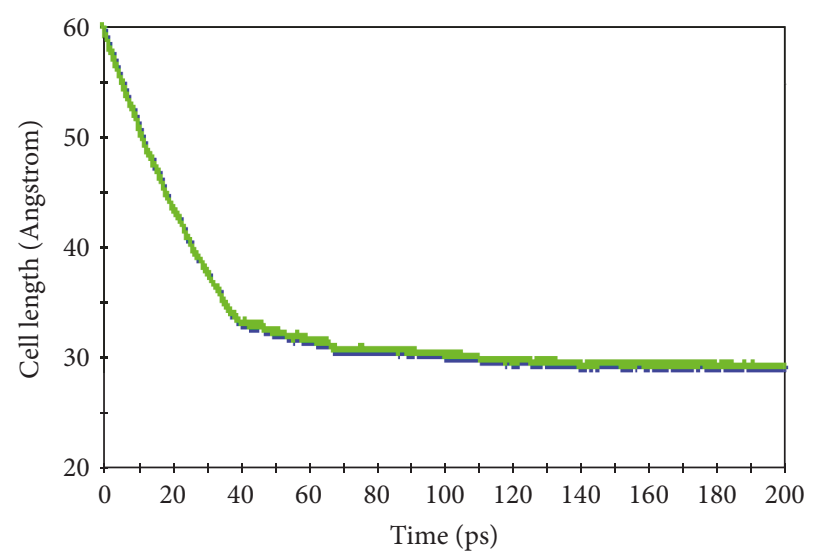

(b)

FIgURE 10: Change of (a) system density and (b) system length of side with time at $0.01 \mathrm{GPa}$.

decrease the length of side. After optimizing the structure, NVT ensemble was conducted, and subsequently NPT ensemble was conducted stable again under $0.01 \mathrm{GPa}$ and $298 \mathrm{~K}$. The output temperature and energy curves tended to be stable and balanced with the changes of time after dynamics. The changes of density and the length of side of system can be seen in Figure 10.

It can be seen from Figure 10 that the density was increasing continuously, but the trend density curve was not stable. After a NVT balance was conducted to the system to operate NPT ensemble, the pressure increased to $0.02 \mathrm{GPa}$, and simulation time increased to $400 \mathrm{ps}$, and the curve of system density changing with time is shown in Figure 11.

It can be seen from Figure 11 that the density tended to be balanced, which was very close to the actual density at 0.7944, and the compression was stopped immediately. At this moment, the size of model was $29.01 \AA$. The ultimately balanced saturated phenol model is shown in Figure 12.

(2) Stiffness Matrix and Mechanical Parameters of Saturated Phenol. The mechanical parameters of model in Figure 12 were calculated, and the stiffness matrix obtained for saturated phenol is shown in Table 2 .

It can be seen from Table 2 that the values of $\mathrm{C}_{14}, \mathrm{C}_{15}, \mathrm{C}_{16}$, $\mathrm{C}_{24}, \mathrm{C}_{25}, \mathrm{C}_{26}, \mathrm{C}_{34}, \mathrm{C}_{35}, \mathrm{C}_{36}, \mathrm{C}_{45}, \mathrm{C}_{46}$, and $\mathrm{C}_{56}$ are close to 0 , but, for the three groups of $\mathrm{C}_{11}, \mathrm{C}_{22}$, and $\mathrm{C}_{33}, \mathrm{C}_{12}, \mathrm{C}_{13}$, and $\mathrm{C}_{23}$; and $\mathrm{C}_{44}, \mathrm{C}_{55}$, and $\mathrm{C}_{66}$, the values in each group are very

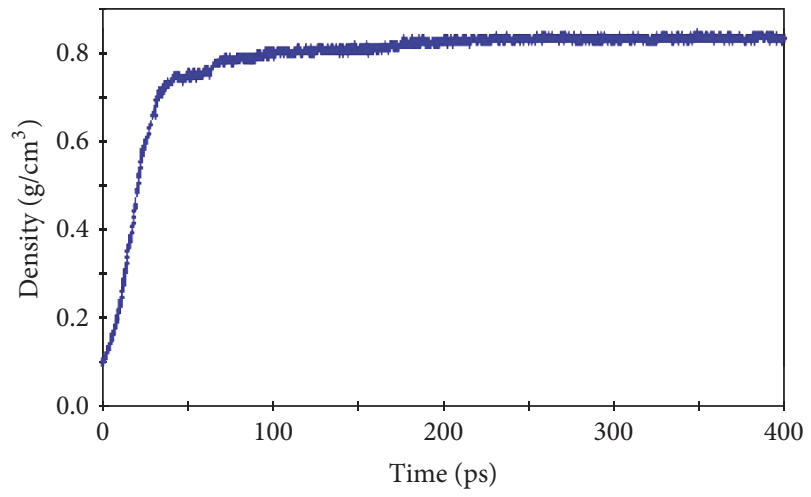

FIGURE 11: Change of system density with time at $0.02 \mathrm{GPa}$.

close, suggesting that the saturated phenol model of Figure 12 is close to isotropy.

Suppose the material is isotropic, and the calculation of lame constant can be seen in

$$
\begin{aligned}
\lambda & =\frac{1}{3}\left(\mathrm{C}_{11}+\mathrm{C}_{22}+\mathrm{C}_{33}\right)-\frac{2}{3}\left(\mathrm{C}_{44}+\mathrm{C}_{55}+\mathrm{C}_{66}\right) \\
& =1.4864 \mathrm{GPa}, \\
\mu & =\frac{1}{3}\left(\mathrm{C}_{44}+\mathrm{C}_{55}+\mathrm{C}_{66}\right)=0.1799 \mathrm{GPa} .
\end{aligned}
$$


TABLE 3: Stiffness matrix obtained for asphaltene model.

\begin{tabular}{lcccccc}
\hline $\mathrm{C}_{i j}$ & 1 & 2 & 3 & 4 & 5 & 6 \\
\hline 1 & 7.8405 & 1.5765 & 1.9309 & -0.3414 & 1.3945 & -0.9280 \\
2 & 1.5765 & 1.8645 & 0.6143 & -0.2868 & 0.4326 & -1.0948 \\
3 & 1.9309 & 0.6143 & 2.5698 & -0.2413 & 0.1393 & -0.0903 \\
4 & -0.3414 & -0.2868 & -0.2413 & 1.1054 & 0.0539 & 0.1551 \\
5 & 1.3945 & 0.4326 & 0.1393 & 0.0539 & 1.2063 & -0.1860 \\
6 & -0.9280 & -1.0948 & -0.0903 & 0.1551 & -0.1860 & 0.8541 \\
\hline
\end{tabular}

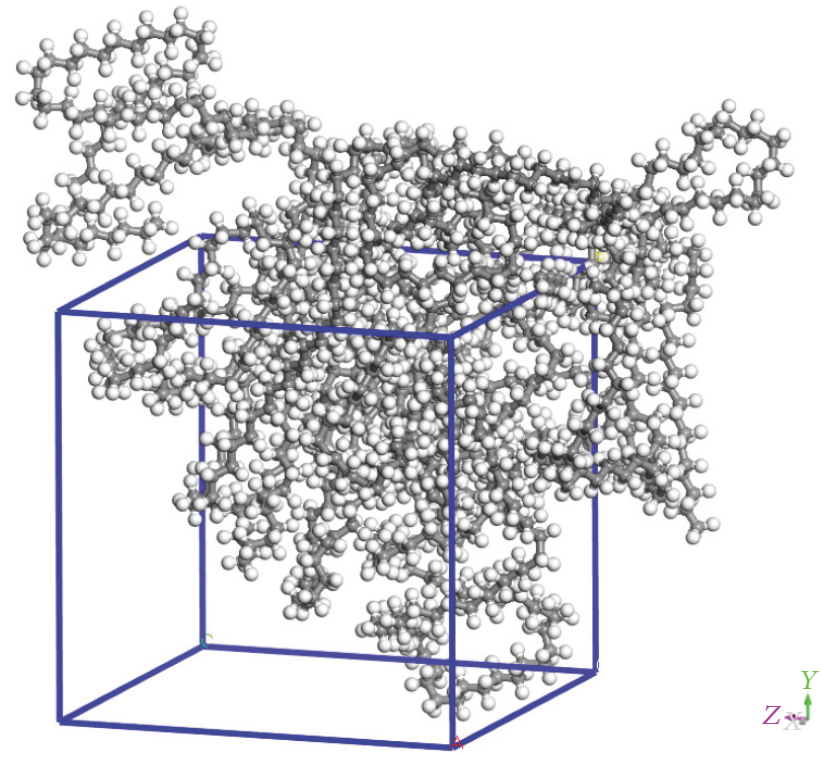

FIGURE 12: Ultimately saturated phenol model.

After substituting $\lambda=1.4865 \mathrm{GPa}$ and $\mu=0.1799 \mathrm{GPa}$ into formula (9), the mechanical parameters of colloid were obtained below:

$$
\begin{aligned}
E & =0.52 \mathrm{GPa} ; \\
\nu & =0.45 ; \\
K & =5.19 \mathrm{GPa} ; \\
G & =0.18 \mathrm{GPa} .
\end{aligned}
$$

\subsection{Mechanical Property Simulation and Analysis of Asphaltene}

(1) Simulation Process and Result of Molecular Dynamics. The $\mathrm{C}_{64} \mathrm{H}_{52} \mathrm{~S}_{2}$ was used to represent asphaltene, and the degree of polymerization at 10 was used to structure asphaltene model. First, the degree of polymerization of asphaltene structure at 10 was placed into the vacuum space where the length of three sides was $6 \mathrm{~nm}$, and the initial density was set at $0.1 \mathrm{~g} / \mathrm{cm}^{3}$. The initial model of asphaltene obtained is shown in Figure 13.

Under the temperature of $298 \mathrm{~K}$, the true density of asphaltene was approximately $0.89 \mathrm{~g} / \mathrm{cm}^{3}$ that the system must be compressed to increase the density and decrease the length of side. After optimizing the structure, NVT ensemble

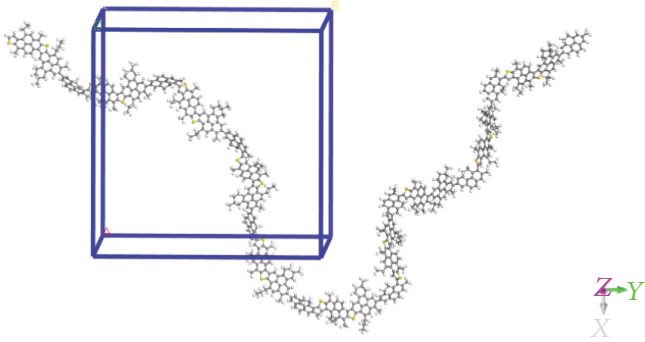

FIGURE 13: Initial model of asphaltene at the density of 0.1.

was conducted. Subsequently, NPT was conducted to stable system under $0.06 \mathrm{GPa}$ and $298 \mathrm{~K}$. The changes of system density and length of side are shown in Figure 14.

It can be seen from Figure 14 that the density was increasing continuously, and it continued to increase. NVT and NPT were conducted to the stable system again, and the pressure increased to $0.08 \mathrm{GPa}$, and simulation time increased to $400 \mathrm{ps}$. The density curve was closed to actual density after the process. At this moment, the compression was stopped. The final output of the asphaltene model is shown in Figure 15. The system density was approximately $0.88 \mathrm{~g} / \mathrm{cm}^{3}$, and the size of three sides of system was around $26.2 \AA$.

(2) Stiffness Matrix and Mechanical Parameters of Asphaltene. After the calculation of mechanical parameters was conducted to the model in Figure 15, the stiffness matrix of asphaltene obtained is shown in Table 3.

Suppose the material is isotropic, and the calculation of lame constant is shown in

$$
\begin{aligned}
\lambda & =\frac{1}{3}\left(\mathrm{C}_{11}+\mathrm{C}_{22}+\mathrm{C}_{33}\right)-\frac{2}{3}\left(\mathrm{C}_{44}+\mathrm{C}_{55}+\mathrm{C}_{66}\right) \\
& =1.9811 \mathrm{GPa}, \\
\mu & =\frac{1}{3}\left(\mathrm{C}_{44}+\mathrm{C}_{55}+\mathrm{C}_{66}\right)=1.0553 \mathrm{GPa} .
\end{aligned}
$$

After substituting $\lambda=1.9811 \mathrm{GPa}$ and $\mu=1.0553 \mathrm{GPa}$ into formula (9), the mechanical parameters of colloid were obtained below:

$$
\begin{aligned}
E & =2.80 \mathrm{GPa} ; \\
\nu & =0.33 ; \\
K & =2.61 \mathrm{GPa} ; \\
G & =1.05 \mathrm{GPa} .
\end{aligned}
$$




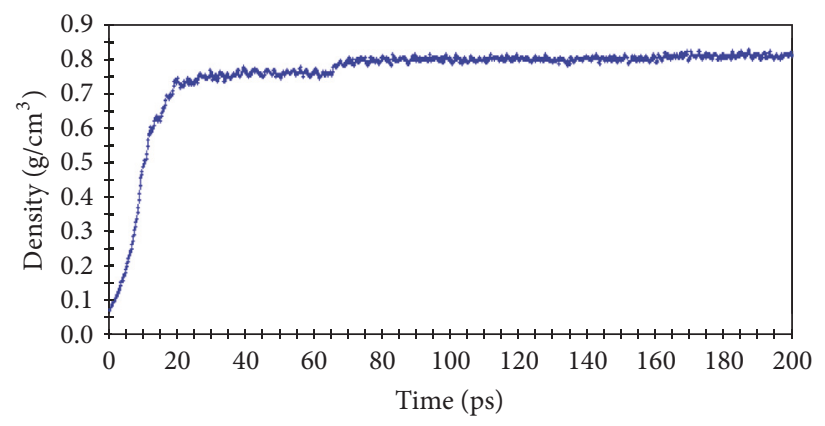

(a) System density

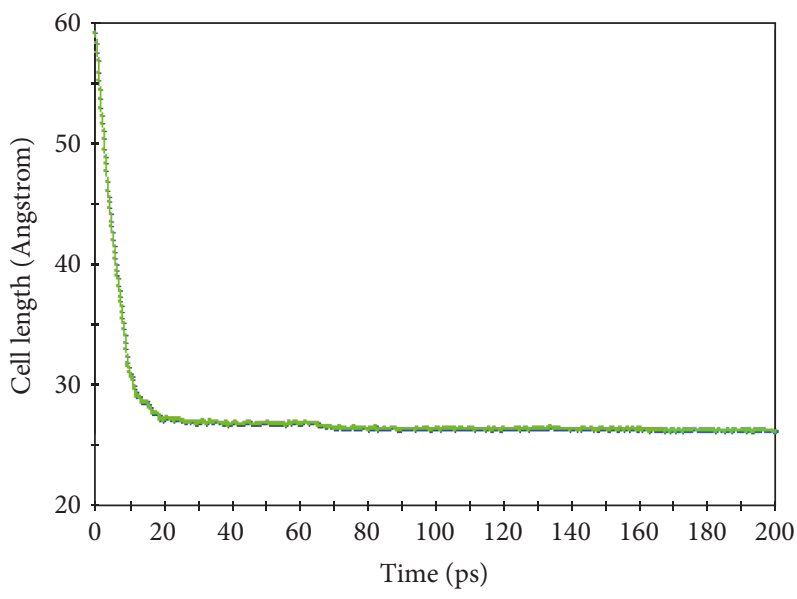

(b) System length of side

FIGURE 14: Change of (a) system density and (b) system length of side with time at $0.06 \mathrm{GPa}$.

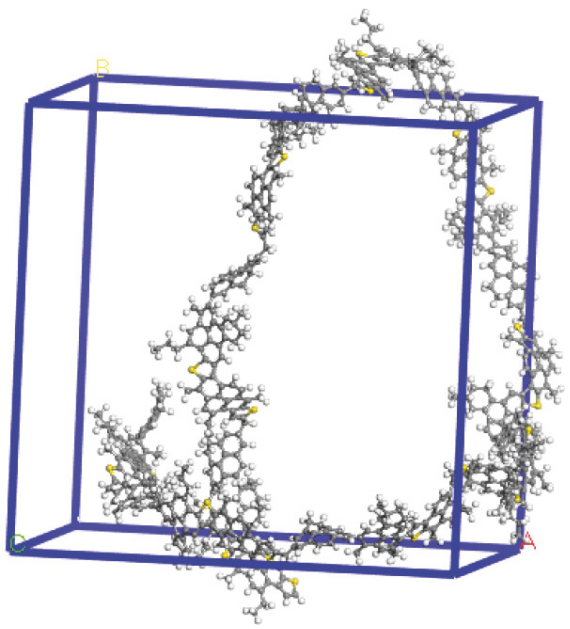

FIGURE 15: Ultimate model of asphaltene.

\section{Conclusions}

The calculation of mechanical properties was conducted to the groups of colloid, saturated phenol, and asphaltene, respectively, and the parameters of stiffness and modulus of all the materials were obtained. Comparing the $E$ value of Young modulus of these three polymers, the maximum modulus value of asphaltene was $2.80 \mathrm{GPa}$, the modulus value of colloid was secondary, and the minimum modulus value of saturated phenol was $0.52 \mathrm{GPa}$. In asphalt, asphaltene is similar to solid, and Young's modulus is largest, followed by colloid. Saturated phenol is similar to liquid, of which the modulus is far less than asphaltene. In addition, comparing the values of Poisson's ratio, it can be found that the maximum Poisson's ratio of saturated phenol is 0.45 , which is close to 0.5 , further suggesting that saturated phenol is similar to liquid that it is incompressible. However, more molecular morphologies require further investigation.

\section{Conflicts of Interest}

The authors declare that there are no conflicts of interest regarding the publication of this paper.

\section{Acknowledgments}

The research was supported by the National Natural Science Foundation of China (Grant nos. 51378073 and 51408048), the Key Program for Science and Technology Projects of Shaanxi province (Grant no. 2017KCT-13), the science and technology projects of Shaanxi Provincial Transport Department (Grant no. 15-35T), and the Special Financial Grant from the China Postdoctoral Science Foundation (Grant no. 2016T90880).

\section{References}

[1] A. Bhasin and D. N. Little, "Application of microcalorimeter to characterize adhesion between asphalt binders and aggregates," Journal of Materials in Civil Engineering, vol. 21, no. 6, pp. 235243, 2009.

[2] J. Yu, X. Zeng, S. Wu, L. Wang, and G. Liu, "Preparation and properties of montmorillonite modified asphalts," Materials Science and Engineering: A Structural Materials: Properties, Microstructure and Processing, vol. 447, no. 1-2, pp. 233-238, 2007.

[3] A. E. Alvarez, E. Ovalles, and A. Epps Martin, "Comparison of asphalt rubber-aggregate and polymer modified asphaltaggregate systems in terms of surface free energy and energy indices," Construction and Building Materials, vol. 35, pp. 385392, 2012.

[4] A. Bhasin, Development of Method to Qualify BitumenAggregate Adhesion and Loss of Adhesion due to Water, Texas A\&M University, College Station, Tex, USA, 2006.

[5] R. Li, H. Du, Z. P. Fan, and J. Z. Pei, "Molecular dynamics simulation to investigate the interaction of asphaltene and oxide in aggregate," Advances in Materials Science \& Engineering, vol. 7, pp. 1-10, 2016.

[6] R. Li, H. F. Wang, P. Wang, H. Liu, and J. Pei, "Influence of PZT piezoelectric ceramics on the structure and electric properties 
of piezoelectric lead zirconate titanate/poly(vinylidene fluoride) composites," Materials Express, vol. 6, no. 6, pp. 483-492, 2016.

[7] D. Cheng, D. Little N, and C. Holste J, "Use of surface free energy of asphalt-aggregate systems to predict moisture damage potential," Journal of Association of Asphalt Paving Technologists, vol. 71, pp. 59-84, 2002.

[8] R. Li, J. Li, Y. C. Xiao, and J. Z. Pei, "Reliability index study of asphalt pavement construction based on analytical hierarchy process," Applied Mechanics and Materials, vol. 470, pp. 884888, 2014.

[9] R. Li, C. C. Wang, P. Z. Wang, and J. Z. Pei, "Preparation of a novel flow improver and its viscosity-reducing effect on bitumen," Fuel, vol. 181, pp. 935-941, 2016.

[10] X. Yu, C. Xiong, Y. You, L. Dong, and J. Yao, "Aromatic azo-polyamide electrolyte with liquid crystal structure and photoelectrical properties," Synthetic Metals, vol. 158, no. 8-9, pp. 375-378, 2008.

[11] S. Yang, J. Choi, and M. Cho, "Elastic stiffness and filler size effect of covalently grafted nanosilica polyimide composites: Molecular dynamics study," ACS Applied Materials \& Interfaces, vol. 4, no. 9, pp. 4792-4799, 2012. 

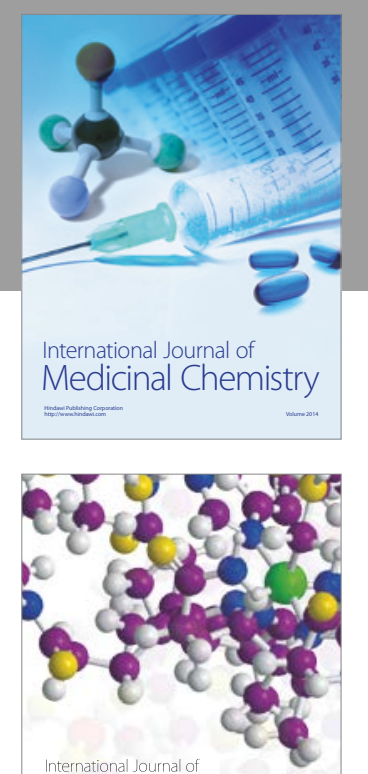

Carbohydrate Chemistry

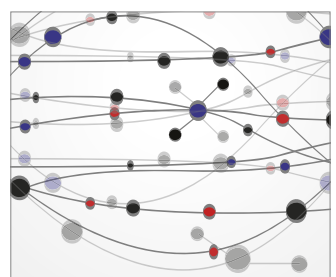

The Scientific World Journal
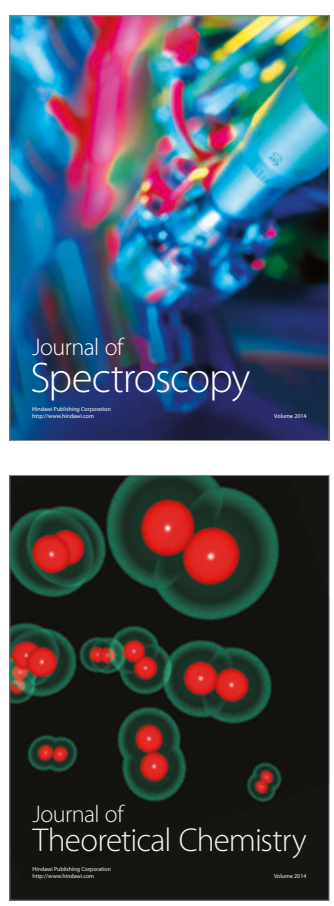
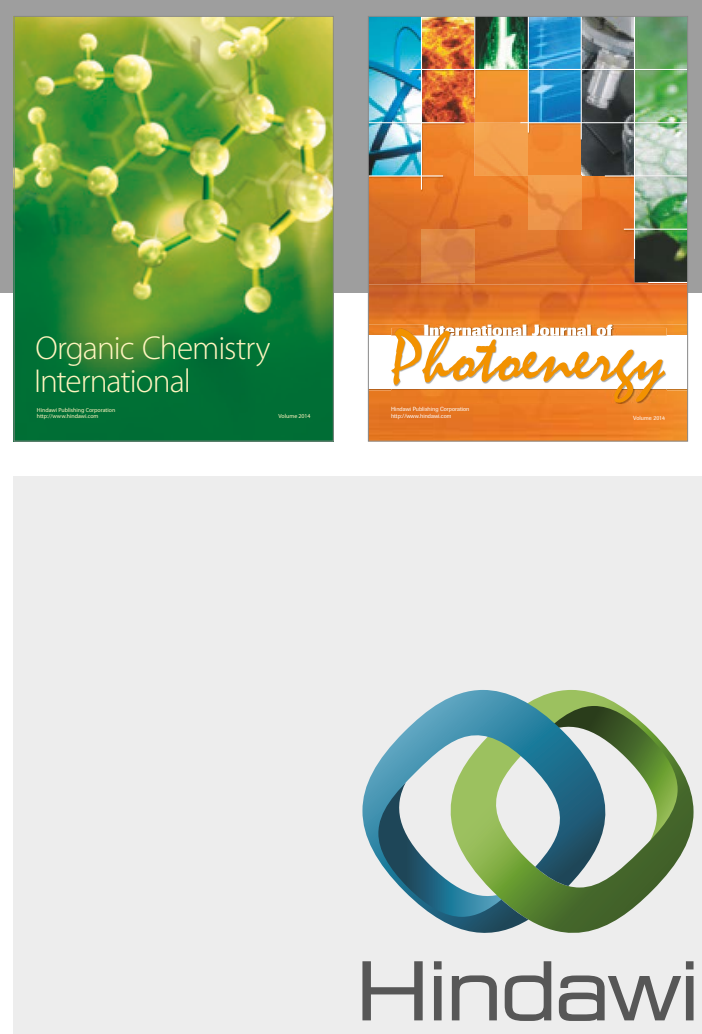

Submit your manuscripts at

https://www.hindawi.com

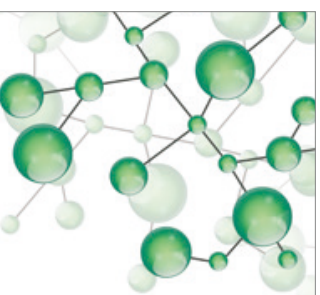

International Journal of

Inorganic Chemistry

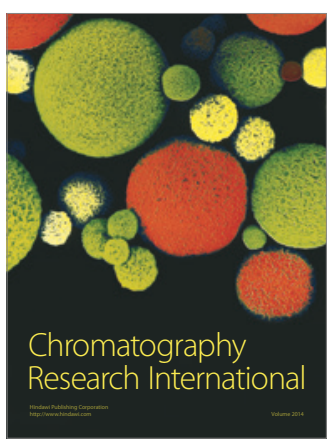

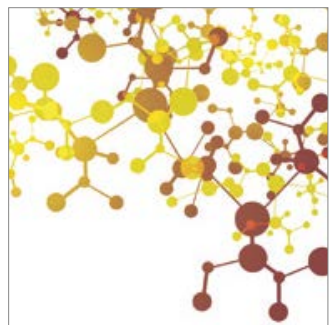

Applied Chemistry
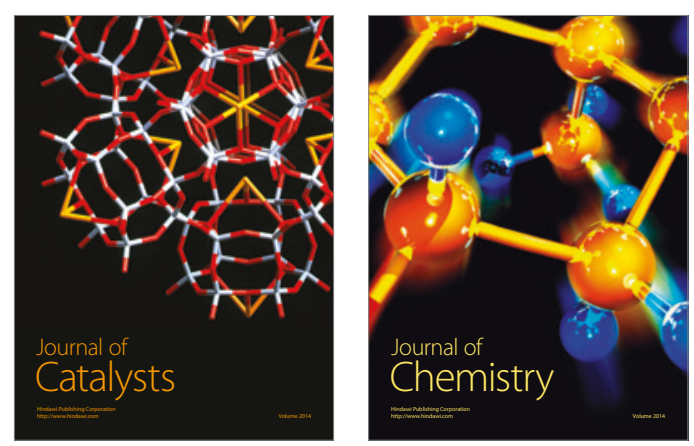
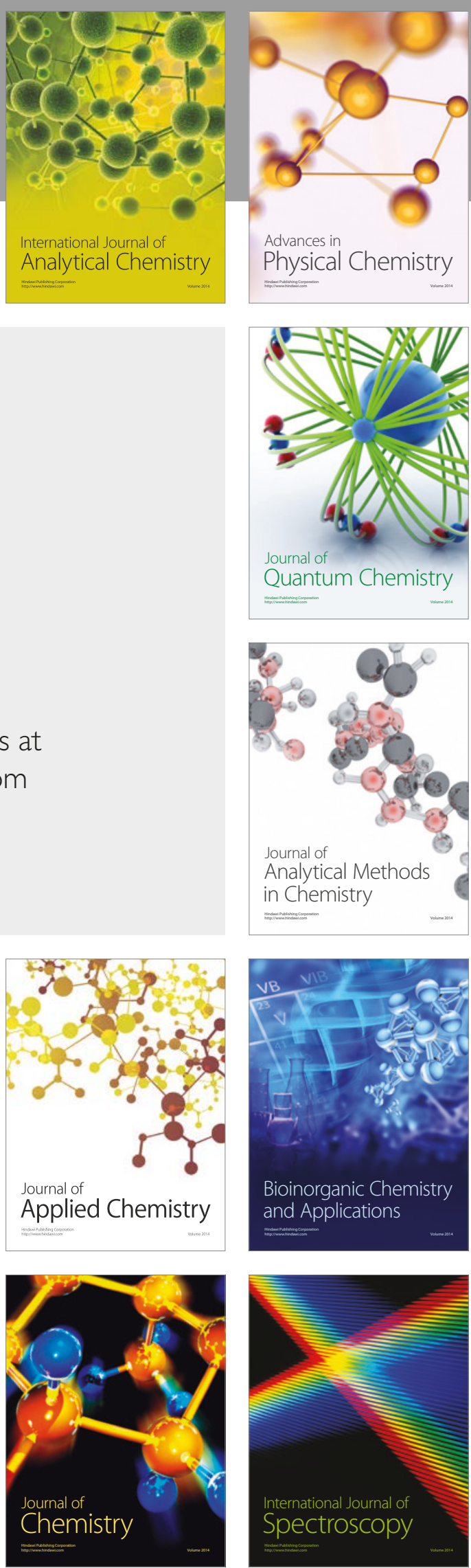